\title{
Investigation of Equipment Elements of the Niğde Ömer Halisdemir University Campus in Terms of Aesthetics and Functional Properties ${ }^{\#}$
}

\author{
Orhun Soydan ${ }^{1, a, *}$ \\ ${ }^{l}$ Landscape Architecture Department, Faculty of Architecture, Niğde Ömer Halisdemir University, 51240 Niğde, Turkey \\ *Corresponding author
}

\begin{tabular}{|c|c|}
\hline A R T I C L E I N F O & A B S T R A C T \\
\hline 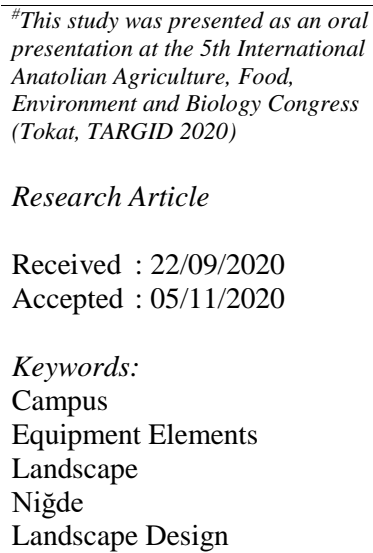 & $\begin{array}{l}\text { In this study, equipment elements which have been used in Niğde Ömer Halisdemir University } \\
\text { campus, were analysed considering various criteria in terms of landscape architecture. In this study, } \\
\text { lighting and flooring elements, trash cans, sitting elements etc. were evaluated considering some } \\
\text { criteria such as maintenance, design, ergonomics, etc. Within the scope of the study, it has been } \\
\text { determined whether the equipment elements in the campus meet the people needs. There are } \\
\text { insufficient number of seating elements in the campus, security problems occur due to the lack of } \\
\text { lighting elements in certain places. The bus stops in the campus are sufficient numerically, and they } \\
\text { are in suitable areas in terms of location. In addition, the number of telephone booths and the number } \\
\text { of trash cans in the campus are insufficient. The designs of the equipment elements are similar, and } \\
\text { equipment elements have traditional design. As paving elements, key paving stones are used on } \\
\text { pedestrian roads, so that in some areas, collapses occur, so fall, snag, etc. on pedestrian roads. } \\
\text { Finally, suggestions for using equipment elements in campus areas were developed. }\end{array}$ \\
\hline
\end{tabular}

\section{Introduction}

The urban equipment elements began to be used in the 1980s by environmental scientists, landscape architects and designers. In addition, the concept of the urban equipment elements was referred to various names such as urban furniture, landscaping elements and urban accessories. In terms of this content, while the urban equipment elements are related to infrastructure, urban accessories are mostly related to decorative elements. Environmental arrangements are also a whole of the different meanings in itself, which includes higher landscape elements (Alpagut, 2005; Yazıc1, 2017). Features that should be known in the urban equipment elements, are that aesthetic and functional, cost-effective, easy-to-find, being in compliance with standards and durable, ergonomic, being original, resistant to vandalism and ecological conditions, having easy spare parts and assembly, workmanship and being suitable in terms of material (Yazıc1, 2007; Külekçi and Irmak, 2019). Urban equipment elements are considered as objects of the use and communication. Urban equipment elements which are also defined as visual objects, are considered as part of the urban identity. The equipment elements are very important in terms of urban design due to their design features and their relationship with the urban areas (Bayraktar et al., 2008).

Urban equipment elements that provide visual richness and identity to the city, help to provide a visual comfort the urban appearance by making the place feel strong (Mair and Taylor, 1999). Equipment elements are also considered as cultural elements as part of the humanvehicle-environmental system. Each equipment element has a feature that defines its location as part of the built environment, as well as a visual object quality for users and a symbolic meaning for the city. For this reason, the fact that the design and production of the urban equipment elements, which play an important role in urban design and urban landscape design, should not be isolated from the planning or design process, should not be ignored, and they should be considered as a whole when they are put together. Urban equipment elements are expected to form a whole by having a common design feature due to their functional similarities. Because of this common design, equipment elements should be considered as a part of continuity and integrity within the city and as an identity 
element that makes the city livable and perceptible (Kuter and Kaya, 2019).

University campuses provide service a large number of the users depending on their density. For this reason, it is important that the urban equipment elements that are used in the university campuses, are shaped according to the socio-cultural characteristics of the region, and designed in accordance with the functions that will meet the user's needs (Güremen 2011; Erdoğan et al., 2011). The urban equipment elements that can be designed differently in each region, are generally lighting elements, seating units, floor coverings, trash cans, barriers, information / sign boards, sculptures, pools, fountains and stops (Bozdoğan et al., 2015).

When we examine the studies on the equipment elements, we can group these studies under theree headings. One of these groups is the studies for determining the aesthetic and functional properties of the equipment elements that are used in urban areas. Kuter and Kaya (2019) examined the qualifications of the equipment elements that were used in the city of Çankırı. Güngör and Oğuzhanoğlu (2019) evaluated of Children Playgrounds in Konya-Kulu District in Terms of Landscape Architecture. In the second group, the suitability of the design of the equipment elements for individuals with disabilities is investigated. Karayılmazlar and Çelikyay (2019) investigated the compatibility of urban equipment elements to universal standards. Güngöt et al. (2019) examined of shopping malls in Konya for the use of children and their families. In the last group, there are studies on determining the contributions of urban equipment elements to the security of the city. Ojani (2019) researched the study on the effects of urban equipment elements on safety and urban aesthetics.

In this study, equipment elements which have been used in Niğde Ömer Halisdemir University campus, were analysed considering various criteria in terms of landscape architecture. In this study, lighting elements, flooring elements, trash cans, sitting element etc. were evaluated considering some criteria such as maintenance, design, ergonomics, etc. Within the scope of the study, it has been determined whether the equipment elements in the campus meet the needs of people.

\section{Material and Method}

The study area covers the Niğde Ömer Halisdemir University within the borders of the Niğde, Turkey. Niğde located in $34^{\circ} 30^{\prime} 10^{\prime \prime}-34^{\circ} 45^{\prime} 00^{\prime \prime}$ eastern longitude and $37^{\circ} 54^{\prime} 00^{\prime \prime}-38^{\circ} 06^{\prime} 30^{\prime \prime}$ northern latitudes (Figure 1). The size of the study area is approximately $2.00 \mathrm{~km}^{2}$ (Figure 2). The Niğde Ömer Halisdemir University campus is preferred by many people due to the fact that it is built on a large area and the social activities which it contains. Niğde Ömer Halisdemir University Campus was selected as the study area in order to determine the problems of the equipment elements, and to develop suggestions to improve the quality of life of the individuals by reducing the problems. Niğde Ömer Halisdemir University campus was selected because it is an urban area that is used for 24 hours and includes in different activities such as accommodation, education, social-cultural centers, sports fields and green areas, and the need for durable equipment elements.

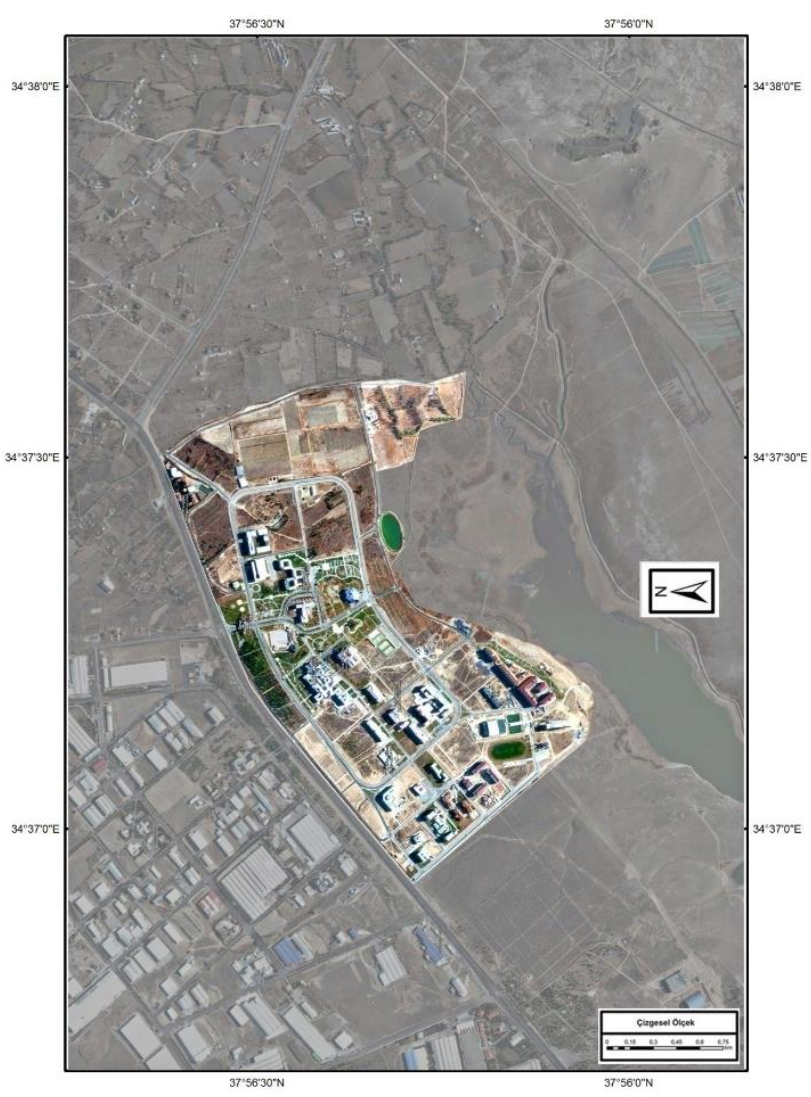

Figure 2. Niğde Ömer Halisdemir University Campus

Figure 1. Location of Nigde in Turkey 
Within the scope of the study, the current maps of the Niğde Ömer Halisdemir University campus were obtained from the relevant units. The current status of the Niğde Ömer Halisdemir University campus was determined over these maps. First of all, the equipment elements which were found in the campus, were determined. The equipment elements in the campus have been examined according to properties of the aesthetically and functionally.

The design errors in the equipment elements were determined, and their suitability for the use of individuals with disabilities was analyzed. In this study, landscape research method based on observation, data collection, analysis and synthesis was used. Within the scope of the study, photographs from the equipment elements in the campus were taken. In the next step, the equipment elements were grouped among themselves taking into consideration the previous studies. Finally, design errors of the equipment elements in the campus were determined, and suggestions were made for suitability for the use of individuals with disabilities.

\section{Results and Discussion}

The equipment elements in the campus were grouped according to their characteristics (Şisman and Yetim, 2004; Bayazit, 2018). The equipment elements were examined under two titles, which are connected to the infrastructure, and not connected to the infrastructure. Lighting elements, telephone booths, bus stops, fountains were defined as equipment elements which are connected to the infrastructure. Playgrounds, seating elements, plant crates, trash cans, flooring elements, restraint elements, shading elements, signs and signboards were defined as equipment element which are not connected to the infrastructure.

\section{The Equipment Elements Connected to The Infrastructure}

\section{Lighting Elements}

Campus have the lighting elements which has different features according to land use. Lighting elements of 11-12 meters in length on main roads, and 8 meters in length on intermediate roads are used.

While lighting elements with a length of 3 meters are preferred on pedestrian roads, lighting elements with a length of 1 or 3 meters are preferred in landscape areas. While concrete poles are generally preferred in lighting elements, it is possible to see examples of metal poles. It is possible to see LED and eco lamp types as well as sodium or mercury vapor lamps in the campus. There are problems in terms of lighting in some areas due to reasons such as negligence and deterioration in the campus. Lighting elements cannot reflect the identity of the campus in terms of aesthetics. The sequential rhythm, which is formed by repeating the in regular rows, dominates the lighting elements, and there is repetition, balance and emphasis by the design principles. Although the material and color which are used in the lighting elements, are integrated with the texture of the campus, the designs are not unique when evaluated for suitability and authenticity. Lighting elements that are used in the vehicle roads, comply with the standards in terms of size and ratio, but its lack of human scale affects its functionality and aesthetics negatively.
There is no lighting design in Akkaya Dam, which is of great importance within the campus. Lack of lighting design in such an area was found to be quite incomplete in terms of visual quality of the campus. However, we can say that lighting on pedestrian and vehicle roads is partially sufficient. Lighting examples in the campus are given in Figure 3.

\section{Bus Stops}

There are a total of 6 bus stops on the campus. This number was found insufficient due to the absence of a bus stop near the some administrative and academic buildings in the campus. The bus stop on the campus is considered sufficient in terms of aesthetics and environmental compatibility. In the design of bus stops, inox and glass were used as materials. There is a wooden sitting element inside the bus stops.

There is no compliance problem among the materials. Side frames of the bus stops are used for advertising or information purposes. This features adds functionality to bus stops. Bus stops in the campus are given in Figure 4.

\section{Telephone Booths}

Although telephone booths are no longer popular as the return of the communication process, their use in urban areas is important and necessary. Due to the increase in the use of smart devices with technological advances, equipment elements, telephone booths, which provide the charging of devices designed with solar panels in the cities, can take place in time (Bayazit, 2018). There are 2 types of the telephone booths in the campus. One of them is not built on pedestrian roads or sidewalks, but they were built in a certain area.

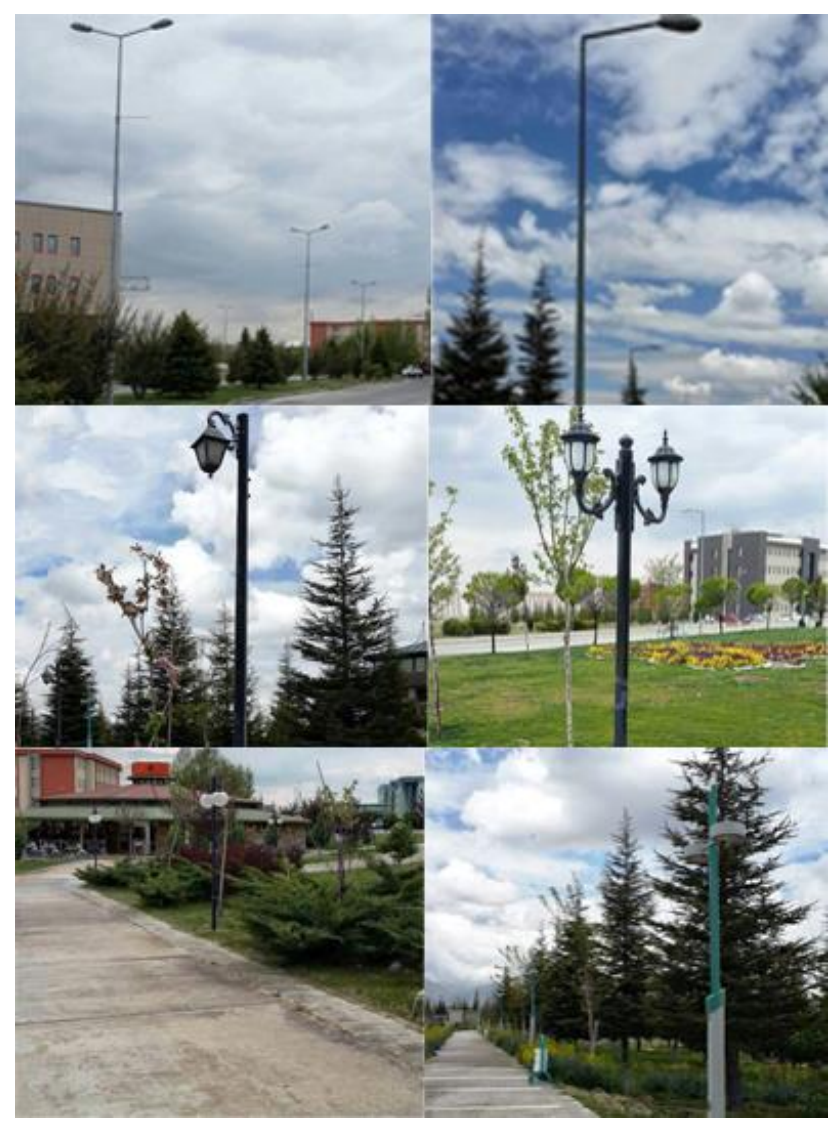

Figure 3. Lighting examples in campus 

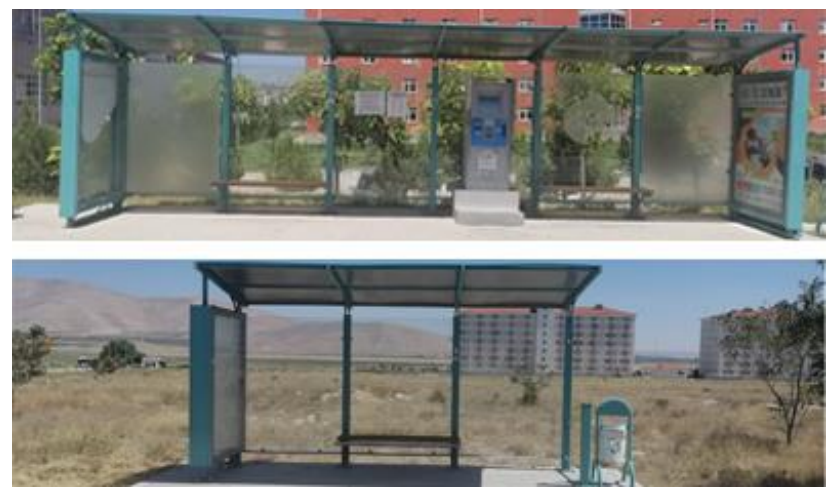

Figure 4. Bus stops examples in campus

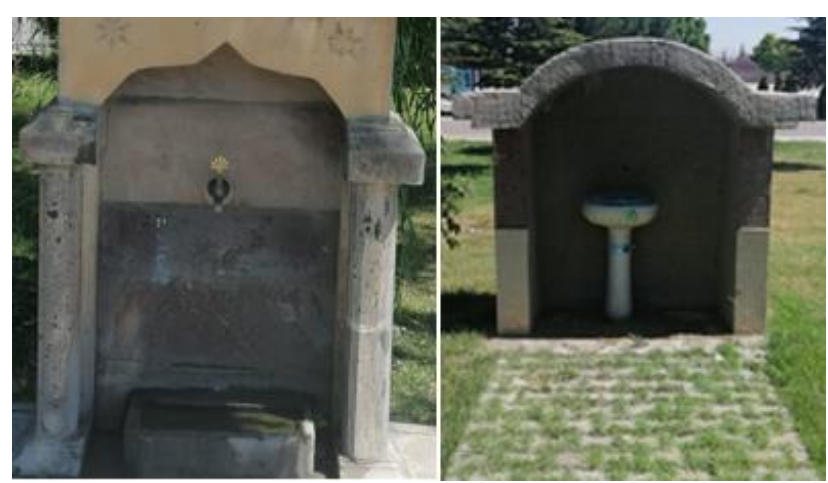

Figure 5. Fountains in campus

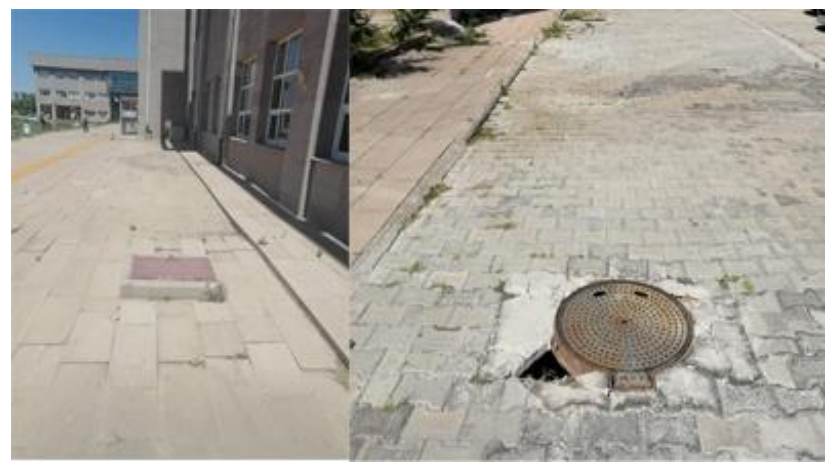

Figure 6. Infrastructure facilities covers

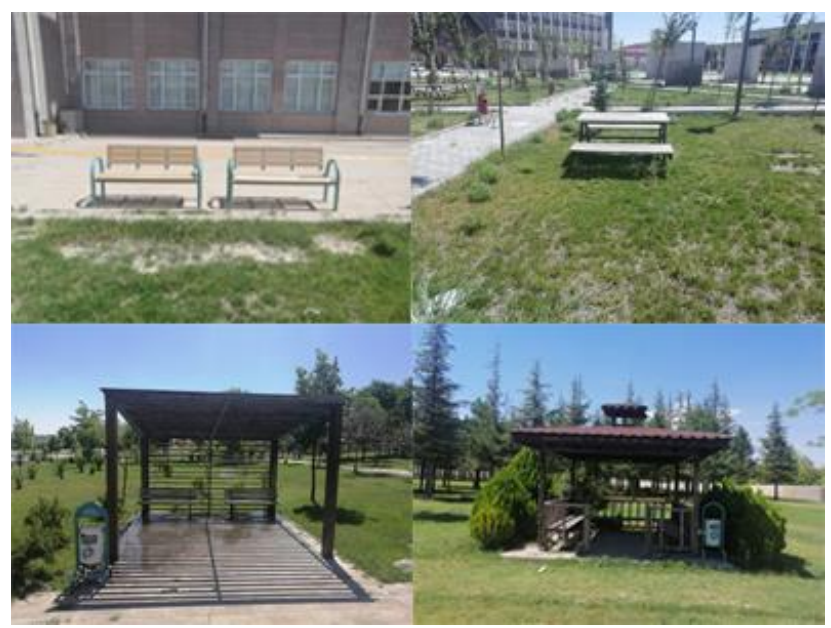

Figure 7. Seating elements in campus
These booths are covered with glass materials. These models are functional and do not have any aesthetic value. They do not seem compatible with their environment in terms of material, color, and form. In addition, these booths are neglected and dirty, also they harm the visual quality of the campus. The second type of the booths are located in the western parts of the campus, and prevent pedestrian circulation in the middle part of the pavement.

The semi-enclosed telephone booth type is neglected and has a rather bad appearance with the remains of information paper adhered on it. These booths are covered with metal materials. Although the telephone booths in the study area are incompatible with the surrounding equipment, the measure-ratio relationship is also in a design suitable for human scale.

They don't have an original design that will contribute to urban aesthetics and identity or carry its texture. Although the telephone booths are compatible with each other in color and material, they have aesthetically ordinary and similar features with other cities. It has been determined that the booths, which do not have an aesthetically beautiful appearance, cannot also provide functional features such as seating or lighting.

\section{Fountains}

In the study area, there are 3 fountains with similar designs. One of them is at the entrance of the campus, the other is near the dining hall and the last one is in the area where the student residence are located. The locations of the fountains in the campus do not affect the pedestrian roads. The color of the material that was used for the fountains, is in harmony with the area and urban texture. Their designs are not unique. No incompatibility was observed in the measure-ratio balance with the areas and the human scale.

Functionality is at the forefront of the fountains and they do not have an aesthetically high quality appearance. The fountains in the campus are made of natural cut stones as materials. The fountains are on a human scale and it is determined that they are compatible with the historical texture of the campus. However, it was determined that the fountains were insufficient for the originality. Fountains are sufficient in terms of location, perceptibility, maintenance, unity and integrity. Fountains in the campus are given in Figure 5.

\section{Infrastructure Facilities Covers}

These are the covers placed on the ground in order to reach the arrangements and maintenance of the infrastructure installations such as gas, city water, telephone, electricity, sewage and rain water in urban areas. There are manhole covers, communication covers and gas covers in the campus. Iron was preferred as material. They are generally located on pedestrian or vehicle roads. This causes problems in terms of functionality. The fact that it was covered with iron material made these equipment lacking in terms of aesthetic appearance. In addition, it was determined that collapses occurred in these equipment due to negligence, and they caused problems in terms of functionality in the campus. Infrastructure facilities covers in the campus are given in Figure 6. 


\section{The Equipment Elements Not Connected to The Infrastructure}

\section{Seating Elements}

The sitting elements in the campus were made by the Municipality of Niğde. It was observed that generally the same type of the seating unit was used in the campus. Seating elements are located in the campus in 3 different ways. One of them is the sitting elements under the bus stops. These seating elements are under the shading elements, and are made of wood. While the materials of the bus stops are concrete, the seating units are wooden, which does not provide an aesthetically beautiful appearance. Some seating elements have problems due to wear, breakage, etc. Seating elements in the bus stops were found to be sufficient in terms of functionality. While observing the aesthetic evaluation principles again, it was determined that there was no certain rhythm and balance.

Other sitting groups are located under the shading elements in certain areas in the campus. These seating elements are also made of wood. Since the shading elements which are surrounding them, are also wooden, an aesthetically beautiful view emerges.

In addition, flowers which located in the near these seating units, add visual richness to the areas. These seating elements, which were found suitable for functionality, were found insufficient numerically. Increasing the number of such seating elements in the campus will provide quality to campus. In the last group, there are only sitting elements used as benches. They are generally located in landscape areas or pedestrian roads. Wood was preferred as the material, but it is possible to see metal samples in the campus. We can say that these seating elements have an aesthetic appearance in themselves. However, they cannot show integrity in their areas. These seating elements are sufficient numerically and functionally suitable. Seating elements form integrity in the campus with repetitive and sequential rhythm.

The original seating elements reflect the urban texture and identity with wooden material and the use of wooden materials in the seating units is suitable for the weather conditions of the city. It is compatible with lighting, flower bed and trash cans around the equipment where wooden materials are used, and its compatibility with the environment is good. Seating elements in the campus are given in Figure 7.

\section{Plant Crates}

Plant crates are used as a limiting element and aesthetic feature by creating a composition with the plant for most places (Sağlık et al., 2014). Plant crates in the campus are positioned so as not to interrupt pedestrian roads. Plant crates are mostly on green areas. They add aesthetic value to the campus with the colorful flowers. Although they have a harmony among themselves, they do not have a unique design.

They provide integrity in the campus in terms of color, material and environmental compatibility. In addition, functionality is provided to plant crates by using a limiting element in certain areas. In some areas, plant crates were supported with ground lighting, and a beautiful appearance was provided. Because they are at eye level in human scale, they provide detectability. Plant crates in the campus are given in Figure 8.

\section{Trash Cans}

3 types of the trash cans were identified in the campus. The differences in form and design affect the visual aesthetics negatively and an integrity is not provided. All types have different properties in terms of color and shape. There are also different types of trash cans as material. The fact that some of them are on the pedestrian paths, and they are made of different materials affects the visual quality negatively.

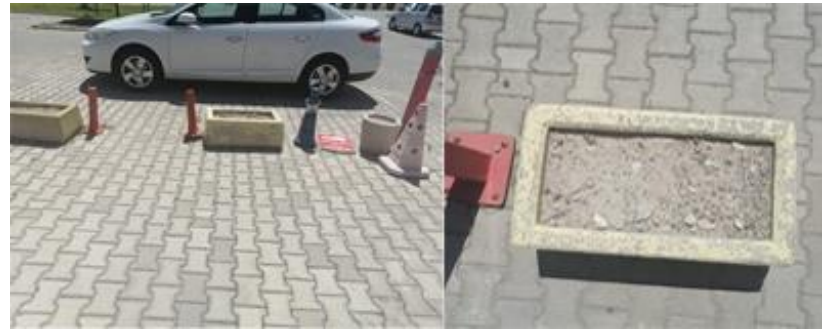

Figure 8. Plant crates in campus

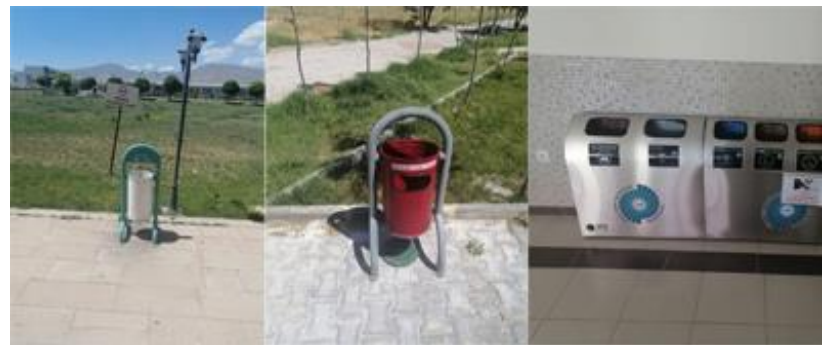

Figure 9. Trash cans in the campus

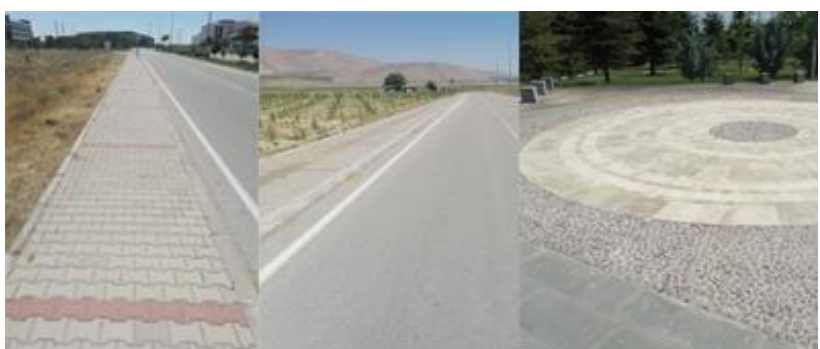

Figure 10. Flooring elements in the campus

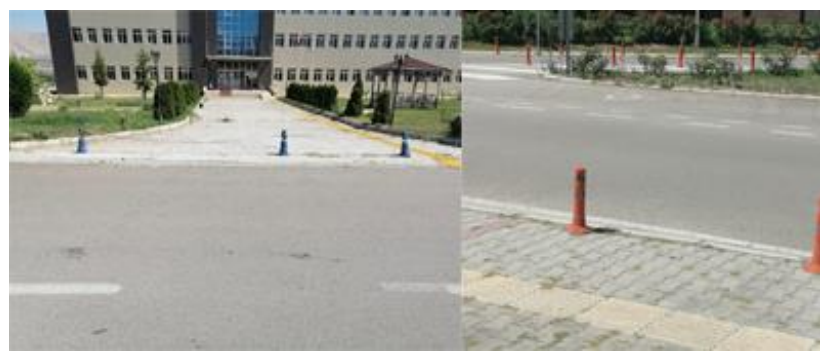

Figure 11. Restraint elements in the campus

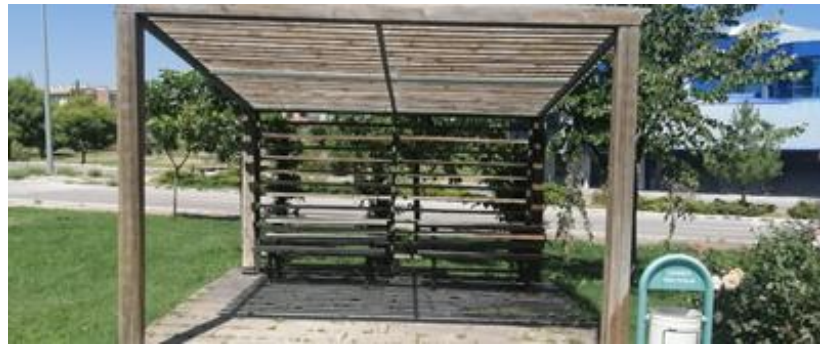

Figure 12. Shading elements in the campus 


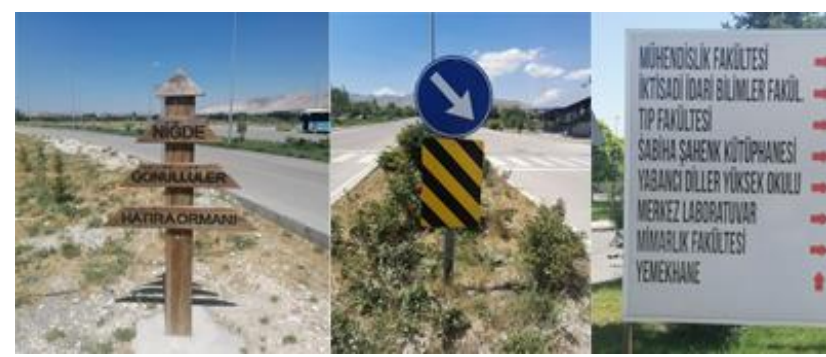

Figure 13. Signs and signboards in the campus

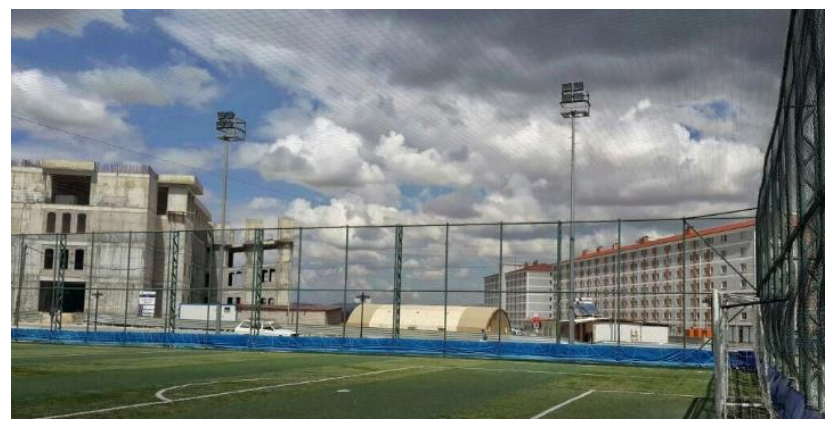

Figure 14. Playgrounds in the campus

Firstly, trash cans on the pedestrian roads were examined in the campus. Pedestrian roads are areas that are used extensively in the campus. Therefore, their positioning on the pedestrian roads was found suitable for functionality. However, it has been determined that some trash cans are located in the middle of the pedestrian roads, thus causing problems in terms of accessibility. In addition, in some areas, trash cans are insufficient numerically. This type of trash cans was generally made of metal, and there is a problem of compatibility with their environment. They are suitable for standards in terms of size. But most of them has a worn out appearance due to reasons such as neglected, vandalism, etc. This causes aesthetic problems in the campus. In the second group, there are trash cans with half-open mouth. These trash cans are usually at the entrance of the administrative and faculty buildings, and it is also possible to see the examples on the side of the pedestrian roads. These cans are made of wooden material and have an aesthetically beautiful appearance. These trash cans are generally neglected. The trash cans are positioned at the entrance of the building, which students spent a lot of time place, and these provided functionality to them. Finally, there are trash cans in the campus that can be located in the "semi-closed trach cans" group. These trash cans design is not unique. The maintenance criteria are not met and the worn appearance of the material spoils the aesthetic appearance. It does not provide reliability as hygiene. It is at a level that can create integrity with other accessories in harmony with color and environment. The measure-ratio balance is suitable for the environment and human ergonomics. Trash cans in the campus are given in Figure 9.

\section{Flooring Elements}

They are used in planning considering the texture, color, line and form features of floor covering elements. The flooring elements that make up the floor, should complement the space in aesthetic terms, in addition to performing many functions.

The factors that are affecting the choice of flooring material, are the function of the area to be laid, traffic, cost, climate, security, durability and local conditions. Floor coverings can offer aesthetically important visual alternatives besides pedestrian and disabled orientation, pedestrian bicycle and vehicle traffic separation, highlighting space, separating spaces (Başal et al., 1993). Different flooring elements are used for each land use in the campus. Interlocking paving stone was used on pedestrian roads. In some areas, it is possible to see concrete, andesite and natural stone flooring samples. Although it has an aesthetic appearance in visual, there are wear on the floors. This causes problems in terms of functionality. Asphalt flooring was used on the vehicle roads in the campus. As it is more durable than other flooring materials, it has been found suitable to use asphalt flooring in these areas. It is possible to see the areas where concrete materials are used in the vehicle roads. Asphalt flooring, which continues with a single color and material, does not provide highlighting and directing functional features to the campus, even though it provides color and material harmony among themselves. Basalt stone was preferred as paving material. In order to indicate the road level of the sidewalks and to emphasize the entrance of the buildings, it was tried to gain motion with a cream-colored cut stone. Grass was generally used in landscape areas. In some areas, there are soil cover and they are covered only with natural vegetation cover. The gaps which are found in some areas due to irrigation problems, cause a bad image. Yellow stripes of plastic material, which provide the guidance of the visually impaired, were used in the middle of the pedestrian roads. The width of these areas is $40 \mathrm{~cm}$ and they are less than the standard values. The disruptions in some areas of these bands cause problems in terms of transportation of disabled individuals. Its compatibility with pavement material and its integrated design, gives aesthetic values to the campus, while it is functional with its durable material. Although the flooring materials that are used in the campus, are not compatible with their environment in color and shape, they are suitable for functionality. Especially with the maintenance works to be carried out in these areas, the aesthetics and functionality of these areas can be increased. Flooring elements in the campus are given in Figure 10.

\section{Restraint Elements}

The restriction elements are used extensively to separate vehicle and pedestrian traffic, in streets, sidewalks and areas where vehicles are undesirable (Bayraktar et al., 2008). The main functions of the barriers are to provide security and prevent unintentional crossings. Resistance to external climatic conditions, working quietly and fast, working manually in case of power cuts are the features preferred in barriers.

Barriers are often used to create an obstacle for vehicles and to control the passage of vehicles (Sağllk et al., 2014; Bayazit, 2018). There are two types of restriction elements in the campus. One of them is made of plastic material, the other is made of concrete. Since both of the limiting elements are not natural limiting, they are not aesthetics.

In particular, plastic limiting elements damage the aesthetic values of the campus. Functionally, both limiting elements are suitable. They provide a huge obstacle, especially in areas where entrance of the vehicles is not wanted. When we look at the campus scale, the limiting elements do not have a negative effect. 
However, it does not reflect the identity of the city as an originality, but its similar or identical designs can be seen in other cities. Due to its limiting designs with plastic materials, the city harms its aesthetics and identity. Instead of these materials, the aesthetic value of the campus can be increased with natural limiting elements. Restraint elements in the campus are given in Figure 11.

\section{Shading Elements}

It was determined that there are 2 types of shading elements in the campus. One of them is the shadow areas that are created using only pergola. They do not have any sitting units under these areas, and they are used only for shadow purposes. They are made of wooden material and have an aesthetic appearance among themselves and environment. They were found suit in terms of functionality as they provide shade in hot climate. The other type of shading element is in the form of a gazebo and has seating units under. These seating elements are also made of wooden material and have an aesthetic appearance. In some of these occur wear due to vandalism and neglect. This damages the aesthetic appearance of the seating elements. These seating elements were found to be more functional since they contain both shade and seating units. Shading elements in the campus are given in Figure 12.

\section{Signs and Signboards}

Signs and signboards; are informative and guiding elements in order to maintain and maintain order. The equipment that should be made in accordance with the aesthetic criteria, while functionally guiding the cities, gives the aesthetics visual and identity to the cities. The equipment elements in the campus were examined in two groups as signs and signboards. The signboards have been examined in two groups such for vehicles and users. The signboard on the vehicle roads are designed to determine the speed limit. They are made of metal and compatible with the environment. These signboards that was arranged in a row, are suitable for functionality. In terms of users, signboards are designed to locate faculty and administrative buildings. These are also made of metal sheet and have an aesthetic appearance. There are traffic signs on the campus as a signs.

These signs that were built on the edge of the pedestrian roads, are suitable for functionality and their designs are not unique. In addition to these uses, the side walls of the bus stop in the campus are also used as advertising or information area. These functionally useful areas are neglected. Signs and signboards in the campus are given in Figure 13.

\section{Playgrounds}

There are two types of playgrounds in the campus, and they are open and closed form. One of them is in the form of an outdoor sports field, and is suitable for functionality. Especially in the evening, it has an aesthetic appearance with its lighting elements. The other playground is a closed area within the campus and various sports activities can be performed. It has been determined that most of the equipment elements in the campus are suitable in terms of functionality, but they are insufficient in terms of aesthetic values. Especially the maintenance and repair of the equipment elements are not done on time, causing visual pollution in the campus. In addition to negligence, there are aesthetic problems in equipment elements due to vandalism, time-related wear and damage caused by climatic activities. Playgrounds in the campus are given in Figure 14. The study was compared with other studies. Kuşkun (2002) determined that the equipment elements were inadequate, their functions were lacking, they did not contribute to the urban aesthetics, but the people of the city were sensitive to the equipment elements in Erzurum. Şimşek and Yetim (2004) determined that there were problems in terms of aesthetics and functionality in urban equipment elements in their study in Tekirdağ. Alpagut (2005) concluded that there were many different types of equipment elements in the area, they are not designed according to the characteristics and needs of the area, and the equipment elements do not reflect the character of the city. Soydan and Benliay (2016) emphasized that color, shape and texture properties of the equipment elements were as important as the equipment elements functionality in their study.

Bayazıt (2018) determined in his study on Kahramanmaraş Trabzon and Government Streets that urban fittings do not have unique designs, and some fittings such as seating units and artistic objects are incorrect. In this study, since it was determined that the equipment elements in the campus did not have aesthetic and unique values, they were similar to other studies. However, since the equipment elements in the campus are found suitable for functionality, they are separated from other studies.

\section{Conclusion}

Equipment elements allow to make urban life more enjoyable and meaningful, and to create urban comfort and urban aesthetics (Tarakc1, 2003). The identity of the city constitutes each element of the equipment elements whose visual effect is important and these are the elements that make the city livable. Equipment elements, which are the unifying factor, are expected to be in harmony and integrity in the cities and environment to provide unity and integrity, to be functional, original and well-maintained. Thus, it will be ensured that cities with livable, civilized and aesthetic values that meet human needs are created (Bayazit, 2018). The number of the lighting elements that are used in the campus, should be increased. Instead of making the same lighting design for each area, the campus may gain a more aesthetic appearance with different lighting types according to the land use. For example, an aesthetic appearance can be achieved with ground lighting in landscape areas and water surfaces. The hard look of these areas can be softened by lighting the walls with the wall washer technique. Maintenance and repair of the lighting elements in the campus can be done on time. Thanks to this, functionality can be increased as well as economic advantages. The number of bus stops within the campus was found insufficient. First of all, the number of these stops should be increased.

Depending on the land use in the campus, the location and size of the bus stops should be reconsidered and designed accordingly. In the Niğde, especially the winter months are quite cold. Building the stops in a way that can be closed in the winter will increase the functionality of these areas. The number of telephone booths in the campus is insufficient. However, it is sufficient according to the number of users. The biggest problem in these areas is that 
the measures are not suitable for individuals with disabilities. These areas should be designed in accordance with the disabled people. Manhole, natural gas, and electric cover on the campus, cause problems in terms of functionality and aesthetics. These areas should be designed in a way that does not prevent pedestrian transportation. In addition, these areas cause sudden elevation changes on the pedestrian roads. The elevation changes at these points should be corrected by excavation and filling works. The current design of the fountains is unique and compatible with the campus. Only maintenance and repair of fountains will increase the use of them. Floor coverings should be maintained regularly, should not pose a threat to city users and should not disrupt the urban aesthetics. The ramp and routers that meet the accessibility criteria especially for the disabled, should be maintained. Seating elements should be designed to be specific to the area and a good lighting design should be made for these areas. Trash cans that are used in the campus, should also be handled within the integrity of a design, color, texture and material. All of the restriction elements in the campus should be removed. Natural limiters should be preferred instead of these elements. Urban equipment elements should be attentive and original in their designs, and the environmental, color and material harmonies among themselves and the city. They should be analyzed well, and should be regularly maintained for a quality and clean city. The values of the city should be analyzed well and urban equipment elements should be added to these values. Unless urban equipment is unique to the city, there will be a possibility of losing its urban texture and identity. In order to preserve the authenticity of the city, urban equipment elements should be designed taking into account the city identity and aesthetic values (Bayazıt, 2018).

\section{References}

Alpagut Z. 2005. Investigation of Information, Guidance and Marking Elements from Urban Furniture in Public Spaces: The Case of Taksim. Master Thesis, Istanbul Technical University Institute of Science Landscape Architecture, 127p.

Bayazit E. 2018. Investigation of Urban Equipment Elements in Terms of Urban Identity and Aesthetic Values: The Case of Trabzon and Government Streets, Kahramanmaraş. Kahramanmaraş Sütçü İmam University, Institute of Science and Technology, Landscape Architecture Department, Master's Thesis, $173 \mathrm{p}$.

Başal M, Memlük Y, Yılmaz O. 1993. Landscape Construction. Ankara University Faculty of Agriculture Publication No: 1322, Course Book 381, Ankara, 170p.

Bayraktar N, Tekel A, Ercoşkun ÖY. 2008. Classification, evaluation and urban identity relation of urban equipment elements on Ankara Atatürk Boulevard. Journal of Gazi Univ. Engineering and Architecture Faculty, 23 (1): 105-118.

Bozdoğan E. Öztürk S, Korkmaz E. 2015. Asi River (Antakya) Coastal Band Recreation Area Equipment Elements and Determination of User Satisfaction. Turkish Agriculture Food Science and Technology Journal, ISSN: 2148-127X, Volume: 3, Number: 1 p: 45-52.
Çelikyay S, Karayılmazlar AS. 2016. Investigation of Public Spaces in Bartın City Center in Terms of Urban Ergonomics and Urban Identity. Bartın Faculty of Forestry Journal, 18 (2): 224-238.

Erdoğan R, Oktay H, Yıldırım C. 2011. Evaluation of Antalya Konyaaltı City Parks Equipment Elements Designs in Line with User Opinions. Artvin Coruh University Faculty of Forestry Journal, 12 (1): 1-8

Güngör S, Oğuzhanoğlu Z. 2019. Evaluation of Children Playgrounds in Konya-Kulu District in Terms of Landscape Architecture. Turkish Journal of Agriculture-Food Science and Technology, 7(sp3): 83-88. DOI: https://doi.org/ 10.24925/turjaf.v7isp3.\%25p.3229.

Güngör S, Yeter S, Asy1lı H. 2019. Examination of Shopping Malls in Konya for the Use of Children and Their Families. Turkish Journal of Agriculture-Food Science and Technology, 7(sp3): 78-82. DOI: https://doi.org/ 10.24925/turjaf.v7isp3.78-82.3228

Güremen L. 2011. Investigation of Urban Equipment Elements in Terms of Urban Identity and Aesthetics in the City of Amasya. e-Journal of New World Sciences Academy. ISSN: 1306-31112011. Volume: 6, Number: 2, Article Number: 3C0073

Kuşkun P. 2002. A Research on the Use of Equipment Elements in the City of Erzurum. Master Thesis, Atatürk University, Institute of Science, Landscape Architecture, 142s.

Kuter N, Kaya Z. 2019. Evaluation of Urban Equipment Elements in Terms of Landscape Architecture: The Case of Çankırı. Bartın Faculty of Forestry Journal, 21 (1): 81-96.

Külekçi EA., Irmak MA. 2019. Aesthetic and Functional Competencies of Equipment Elements Used in Urban Parks; Erzurum City Example. Iğdır University Institute of Science Journal, 9 (2): 1144-1155.

Mair RJ, Taylor RN. 1999. Bored tunneling in the urban environments. In Fourteenth International Conference on Soil Mechanics and Foundation Engineering. Proceedings International Society for Soil Mechanics and Foundation Engineering (Vol. 4).

Ojani S. 2019. Studying the Effect of Urban Furniture on Urban Safety. Advances in Research, 1-9.

Sağlık A, Sağlık E, Kelkit A. 2014. Investigation of Urban Equipment Elements in Terms of Landscape Architecture: The Case of Çanakkale City Center. 1st International Urban Planning and Architecture-Design Congress, Kocaeli, Turkey, 1023-1035.

Soydan O, Benliay A. 2016. Evaluation of Equipment Furniture's Functional and Design Properties. İnönü University Art and Design Magazine, ISSN: 1309-9876, 6 (14): 1--17. The https://doi.org/10.16950/.

Şişman EE, Yetim L. 2004. Investigation of Equipment Elements in terms of Landscape Architecture in Tekirdag City. Trakya University Journal of Science ISSN 1302 647X, 5 (1): 43-51.

Tarakc1 FN. 2003. Vandalism in Urban Environment: Effects of Vandalism on Bank Design. Master Thesis, Istanbul Technical University Institute of Science Industrial Products Design, 263s.

Yazıc1 Süel AB. 2007. The Importance of Equipment Elements in the Formation of Campus Identity as a Social Environment: Field Study on Başkent University Bağlica Campus. Ph.D. Thesis, Ankara University. Social Sciences Institute Department of Social Environmental Sciences, 199p. 